\title{
Oliver Wells (1931-2013) A Brief Memorial
}

\author{
D. C. Joy ${ }^{1,2}$ and L. Gignac ${ }^{3}$ \\ ${ }^{1}$ Material Science and Engineering, University of Tennessee, Knoxville, TN 37831 \\ ${ }^{2}$ Center for Nanophase Materials Science, Oak Ridge National Laboratory, Oak Ridge, TN 37831, USA \\ ${ }^{3}$ Lynne Gignac, IBM T.J.Watson Research Center, Yorktown Heights, NY 10598
}

Oliver Wells was born in London in 1931 to George and Majorie Wells. His father was the son of, and the personal Secretary to, the author H G Wells and was well-off enough to allow Oliver to go to Marlborough College which was, and still is a rather posh and expensive private school. After graduating from there he taught Radio Technology as a Sergeant in the British Army, developing for himself a deep understanding of the growing science of electronics and then went to the University of Cambridge where he studied Mathematics. After graduating with a BA/ MA in mathematics he then joined the research group of Professor (later Sir) Charles Oatley whose goal was to make a "Scanning Electron Microscope" free from the limitations of the (rather primitive) transmission electron microscopes that were just becoming available at that time. Based on earlier work by Knoll (in Germany) and Zworykin (in the USA) Dennis McMullan had, in 1951, built from war surplus components what was recognizably the first real SEM. When McMullan graduated and left the group Oliver took over and built SEM \#2 which was based on McMullan's original design but incorporated many improvements. This instrument was the tool which he used for his Doctoral Thesis on "Construction of a Scanning Electron Microscope and its application to the Study of Fibers".

During the next few years Oliver made many notable contributions to the development of the SEM including the scintillator backscatter detector later made popular by Vivian Robinson, the value and application of atomic number contrast, the first SEM stereoscopic images, and the use of positive ions to reduce charging effects.

In 1959 Oliver moved from England to the USA and joined Westinghouse where he built an advanced SEM and with which he made some of the earliest studies of semiconductor materials and devices using electron beam induced currents. In 1965 he moved to the IBM Thomas J Watson Research Center in Yorktown Heights, NY and immediately purchased a commercial SEM instrument, number 2 off the assembly line, from Cambridge Scientific. Using this instrument he made further significant contributions to the technology of the SEM including the technique of ' low loss' imaging, techniques for efficient backscattered imaging, and developed some of the earliest techniques for the electron beam testing of semiconductor devices. His book on the SEM published in 1970 was the first comprehensive treatise on the topic of scanning electron microscopy and he also published 140 papers. He was MAS President in 1980, and later was elected to the rank of an MAS Fellow. He also became a Fellow of the Royal Microscopical Society of London. Following his official retirement he became an IBM Watson Laboratory Fellow Emeritus and continued to work in the field of microscopy.

Oliver was also very active in other, unrelated, areas. He was an avid cave explorer and cave diver. He built his own oxygen breathing apparatus from war surplus scrap materials and set a record by becoming the first person to dive through the submerged passages known as "Stumps 4 and 5" in 'Swildon Hole' in England in the 1950s. He also went further than anyone else when exploring the underground river of 
nearby ' Wookey Hole'. Later he volunteered his time for the Peekskill Hospital, and for the Yorktown Volunteer Ambulance Unit, and became a part-time ski instructor at Hunter Mountain.

He is survived by his wife Pamela and his children John Craig, and James and Julia

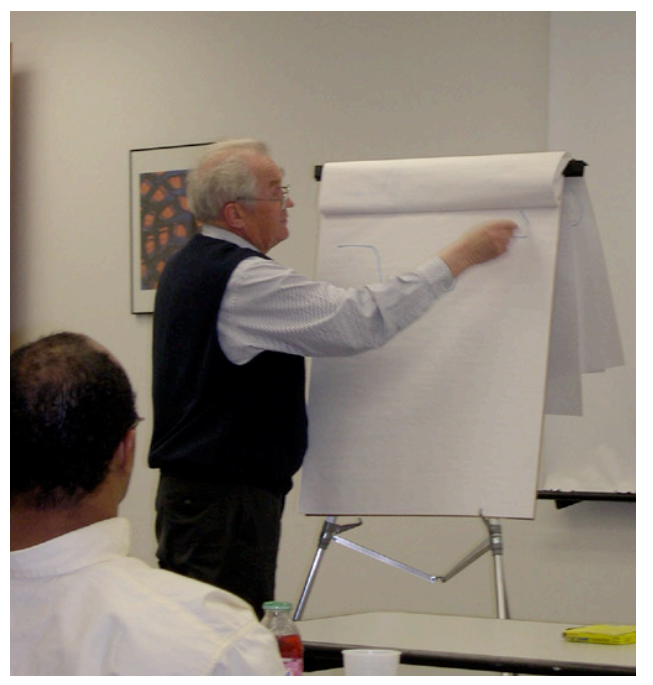

Figure 1- Oliver Wells researcher and teacher 